Article

\title{
Eight Hundred Years of Drought and Flood Disasters and Precipitation Sequence Reconstruction in Wuzhou City, Southwest China
}

\author{
Yinjun Zhao ${ }^{1,2}{ }^{\mathbb{D}}$, Nan Yang ${ }^{2}$, Yongping Wei ${ }^{1,2,3}$, Bo Hu ${ }^{1, *}$, Qizhi Cao ${ }^{1}$, Kai Tong ${ }^{1}$ \\ and Yulian Liang ${ }^{2}$ \\ 1 Key Laboratory of Environment Change and Resources Use in Beibu Gulf, Ministry of Education, \\ Nanning Normal University, 175 Mingxiu East St., Nanning 530001, China; crpp0104@163.com (Y.Z.); \\ yongping.wei@uq.edu.au (Y.W.); qzhcao77@163.com (Q.C.); ktong@gxtc.edu.cn (K.T.) \\ 2 School of Geography and Planning, Nanning Normal University, 175 Mingxiu East St., \\ Nanning 530001, China; gisyangnan@163.com (N.Y.); ratia_lian@163.com (Y.L.) \\ 3 School of Earth and Environmental Sciences, the University of Queensland, Brisbane 4067, Australia \\ * Correspondence: hubo7129@163.com; Tel.: +86-137-3714-6320
}

Received: 4 January 2019; Accepted: 26 January 2019; Published: 28 January 2019

\begin{abstract}
Natural hazards such as floods and droughts occur frequently in southwestern China and have occurred more frequently in recent years, which has caused and will continue to cause serious damage to ecosystems and human lives and property. A full knowledge of the probability of hydro climatic variables is essential for the prevention and mitigation of natural hazards in return. Based on historical archives, atlases and other documented data, a sequence of graded drought and flood disasters covering the period 1250-2000 in Wuzhou City, southwest China, was reconstructed. Then, a correlation coefficient $(-0.79, p<0.01)$ was established between the sequence of grades and the measured annual precipitation from 1961 to 2000; using this correlation and the sequence of grades from 1250 to 2000, the annual precipitation record (from 1250 to 2000) was reconstructed and extended. Finally, we compared the reconstructed annual precipitation to the measured values from 1961-2000 to evaluate the efficacy of this method. The results show that the reconstructed precipitation sequence is credible, with a high correlation coefficient $(0.84, p<0.01)$ and a low relative bias $(-1.95 \%)$. The reconstructed results indicate that the annual precipitation in Wuzhou City increased continuously during the 13-15th century and the 18-19th century and decreased during the 16-17th century and the 20th century. These results are expected to be useful for the prevention of flood and drought impacts and for understanding climate change.
\end{abstract}

Keywords: drought and flood; precipitation; reconstruction; Wuzhou

\section{Introduction}

In recent years, the international community has developed widespread concern over global climate change. Historical changes in precipitation are important parameters that respond to climate change. However, in most parts of the world, precipitation records are relatively short. For example, China's precipitation record is relatively complete since the 1950s, while the longest recorded US record does not exceed 150 years [1]. Climate change is often measured the centennial and millennial scales. In the absence of measurement data from the historical period, surrogate materials such as documents, ancient sites and maps produce long-term hydrological variables and variable data sets of associated environmental subsystems, including hydrology, land use, human activities and ecological data. These materials provide basic data and aid in understanding the historical evolution of these elements and the interactions among them. 
The reconstruction of hydrological regime is the key to studying hydrological and climate changes and the development of human society in the historical period. It is the basis for understanding the evolution of the natural environment and the relationships among human activities at different time scales and aids in improving current management practices and forecasting the future [2]. For example, Lu et al. [3] used reconstructed precipitation and runoff data from the Heihe River basin to quantitatively analyze the evolution of the human-water relationship over the last 2000 years. A wide range of historical documentation and tree ring, lake sediment, ice core and sporopollen data can be employed to reconstruct past conditions [4]. In 1972, Zhu [5] used a record of historical disasters and a phenological history to establish a 5000-year temperature curve for eastern China. Later, a large number of high-resolution sequences of temperature change were reconstructed based on rich historical data and diverse natural evidence such as tree rings, ice cores and stalagmites [6-8]. Mock [9] reconstructed the temperature and precipitation of the northeastern United States and the Rocky Mountains for the summer of 1849 based on 84 western traveler and Mormon diaries. Rodrigo et al. [10] attempted to reconstruct historical rainfall from 1601 to 1650 using historical documents from Andalusia (southern Spain). Compared with the reconstructed temperature, the work of the reconstructed precipitation is slower and their results are also different. This is because precipitation is influenced by many factors, has various types and exhibits a large range variation, all of which increase the difficulty of precipitation reconstruction. In contrast, the eastern part of China has rich and informative historical records, which can provide a large amount of substitute data for research on precipitation change; therefore, research on precipitation change in this region is relatively substantial. For example, Zhang et al. [11] found that there were two mutations in the drought and flood climate in China over two thousand years; Zhang et al. [12] used historical climate records to reconstruct the regional dry-wet climate conditions for nearly 1000 years in the eastern region of China and analyzed the climate changes, cycles and characteristics; Rong et al. [13] and Ren et al. [14] used historical drought and flood data to reconstruct precipitation over 500 years in north China and nearly 2000 years in the Heihe River basin and then reconstructed the temporal and spatial change of precipitation; Zhang et al. [15] reconstructed the frequency of flooding in the Pearl River basin for a nearly 1000-year period based on historical data. Unlike tree rings, lake sediments, ice cores and sporopollen, historical documents do not require harsh conditions because China has a long documented history and it occupies a vast area [16].

The importance of reconstructing the variability in precipitation over the past 1000-2000 years is increasingly recognized [17]. However, most hydrological reconstructions from China are concentrated in the northern region $[17,18]$ and southwest China (e.g., Guangxi) still lacks precipitation reconstructions.

Therefore, this study focuses on Wuzhou City, Guangxi, southwest China, which has a long history and is a representative location in which to reconstruct precipitation changes over the past 800 years based on the historical records of floods and drought. The reconstructed record is expected to provide a reference for reconstructions of historical precipitation, climate change and human-water interactions and water resources management in Guangxi.

\section{Materials and Methods}

\subsection{Study Area}

Wuzhou City (between latitudes $22^{\circ} 37^{\prime}-24^{\circ} 18^{\prime}$ north and longitudes $110^{\circ} 18^{\prime}-111^{\circ} 40^{\prime}$ east) is located in the Guangxi Zhuang Autonomous Region. The city floods every year because it is the location at which 784 rivers (approximately 80\%) in Guangxi flow into the Xijiang River, which drains into the South China Sea. It has rich water resources and is also known as the "Water Capital". Thus, it has a long history in the Guangxi Zhuang Autonomous Region and has a rich historical record of floods and droughts because it was affected by most of the floods and droughts that occurred in Guangxi (Figure 1). 


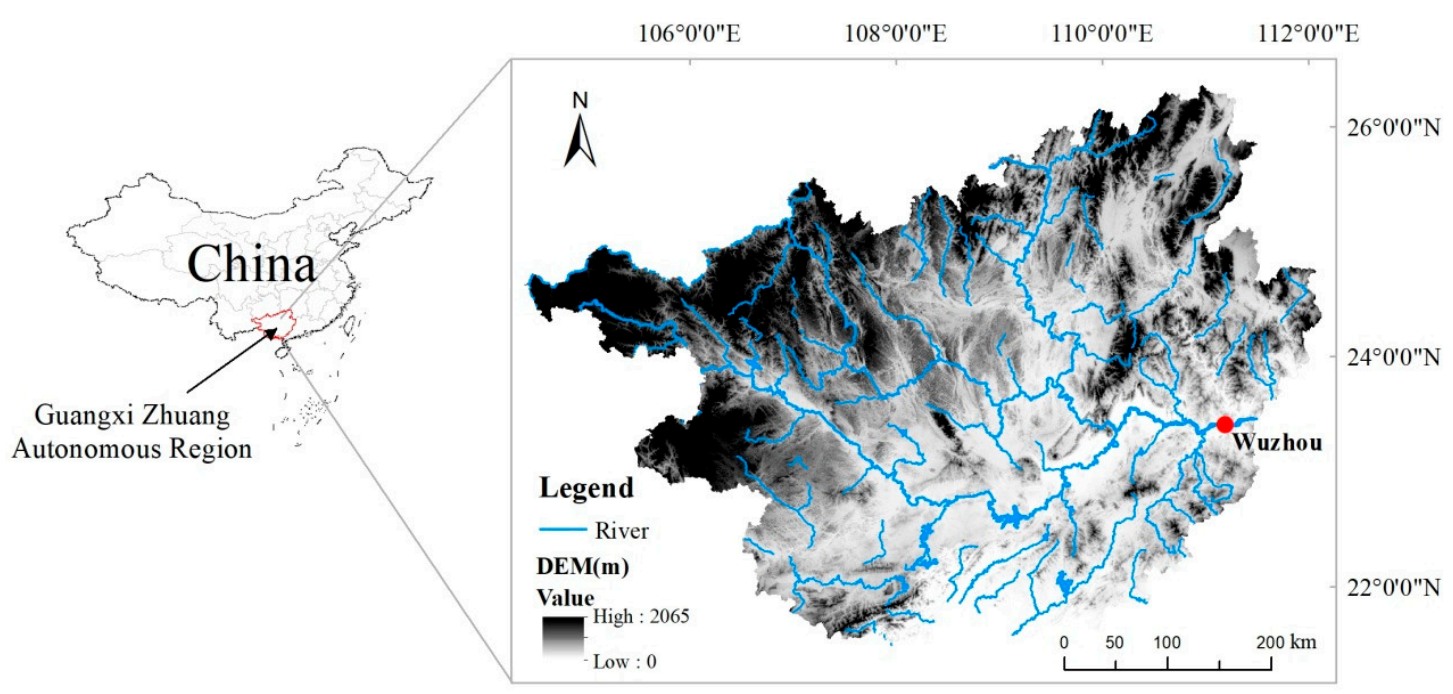

Figure 1. The location of Wuzhou City.

\subsection{Data Sources}

Historical records of floods and droughts in Wuzhou City were mostly collected from the Guangxi Regional Condition (htttp:/ / www.gxdfz.org.cn), which includes the Historical Flood and Drought Records of Cities and Counties in Guangxi, the Guangxi Water Conservancy Chronicles and the Wuzhou Chronicles. The first record from Wuzhou City is from 974. For this study, we selected the period 1250 to 1994, which has a relatively large number of flood and drought records from Wuzhou City. In addition, we used the Yearly Charts of Dryness/Wetness in CHINA for the Last 500-Year Period, which includes continuous replacements (1470-1979, 1980-1992, 1993-2000) [19], to supplement the flood and drought records from Wuzhou City. The precipitation measurements from the Wuzhou meteorological station and other 87 stations in Guangxi from 1961 to 2016 were collected from the Guangxi Meteorological Bureau to validate the reconstructed precipitation or to create the spatial distribution map of annual precipitation of Guangxi through using the Empirical Bayesian Kriging interpolation method in ArcGIS 10.1 that was developed by Environmental Systems Research Institute that is headquartered in Redlands, California, the USA. These precipitation data have undergone quality control procedures to eliminate erroneous and homogenous assessment by the Guangxi Meteorological Bureau. Daily runoffs from the Wuzhou hydrometric station from 1956 to 2000 were collected from the Guangxi Coastal Hydrology and Water Resources Bureau to explain and correct the reconstructed precipitation.

\subsection{Data Preprocessing}

These historical records are verbal descriptions of the flood and drought events; thus, they are usually descriptive and non-continuous. To build a longer record, we synthesized all data sources and then determined a method of replacing missing data. First, we assumed that any year without a flood and drought record was a normal year if the length of missing record was less than 3 years [19]. Second, we used the same-year records from other counties that adjoin Wuzhou City and that had similar average precipitation for nearly 50 years to replace the missing records from Wuzhou City.

A total of 820 records of flood and drought events including 107 records from the adjoined county have been compiled in the period 1250-2000. Specifically for the period 1961-2000, there are 78 records of flood and drought events including 9 records from the adjoined county.

As the most representative document, the Yearly Charts of Dryness/Wetness in CHINA for the Last 500-Year Period [19] was conducted by the Academy of Meteorological Science (1981) to quantitatively study past climate using documented drought and flood events [16]. According to historical description of the degree of severity of the effects of the disaster, the record was generally classified into five grades (grade 1, very wet; grade 2, wet; grad 3, normal, grade 4, dry; and grade 5, 
very dry). This method and the atlas were widely used in many studies. It is also an important source of qualitative information. Thus, the compilation of flood and drought events in Wuzhou City for each year was classified into the five grades to represent the conditions present for each year according to the rules listed in Table 1.

Table 1. Drought and flood classification from the historical description [16,19].

\begin{tabular}{|c|c|c|}
\hline Grade & Standard & Key Words in Historical Records \\
\hline $\begin{array}{c}1 \\
\text { (very wet) }\end{array}$ & $\begin{array}{l}\text { Long-lasting, intense precipitation over } \\
\text { a large area, causing serious loss }\end{array}$ & $\begin{array}{l}\text { Continuous rains in spring and summer; Millions of } \\
\text { people and livestock died in heavy rains in spring and } \\
\text { summer; Continuous heavy rain, the boat can be } \\
\text { driven on land; The field was completely submerged } \\
\text { because of the typhoon and heavy rain }\end{array}$ \\
\hline $\begin{array}{c}2 \\
\text { (wet) }\end{array}$ & $\begin{array}{l}\text { Continuous precipitation with no serious } \\
\text { loss; single-season moderate-lasting local } \\
\text { precipitation; single-day or several-day } \\
\text { more severe precipitation and floods }\end{array}$ & $\begin{array}{l}\text { Continuous rains hurt the standing grain, especially } \\
\text { rice in spring and damaged the crops in autumn; } \\
\text { Sudden flash floods damaged the fields }\end{array}$ \\
\hline $\begin{array}{c}3 \\
\text { (normal) }\end{array}$ & No record of flood or drought, good harvest & - \\
\hline $\begin{array}{c}4 \\
\text { (dry) }\end{array}$ & $\begin{array}{l}\text { Single-season or single-month disasters } \\
\text { with lighter droughts or local droughts; } \\
\quad \text { emergence of hungry people }\end{array}$ & $\begin{array}{l}\text { Spring drought; Autumn drought; Drought in a month; } \\
\text { Drought from May to autumn, people are hungry }\end{array}$ \\
\hline $\begin{array}{c}5 \\
\text { (very dry) }\end{array}$ & $\begin{array}{l}\text { Long lasting severe drought over large area; } \\
\text { serious famine over a large area }\end{array}$ & $\begin{array}{l}\text { Three months without rains; Drought from February to } \\
\text { August; Spring and summer drought with a lot of } \\
\text { desolate land, people ate grass and bark; Summer and } \\
\text { autumn drought, withered crops over a large region }\end{array}$ \\
\hline
\end{tabular}

Based on Table 1, we assigned a grade to each year. The grade of a year with missing data was directly assigned grade 3. During the data processing, some contradictions were resolved based on the following rules: (1) a historical record is considered to present a prior year when it contradicts the Yearly Charts of Dryness/Wetness in CHINA for the Last 500-Year Period; (2) most serious disasters occurred in the year prior when there are several records of flood and drought events for a given year; (3) summer conditions are considered to have occurred in the year prior and to represent the entire year when the record mentioned "arid spring and flooding summer" or "arid summer and flooding autumn"; (4) the gauged runoffs were used to correct the grade of flood and drought when historical records were inconsistent with the gauged precipitations from 1961 to 2000. A total of 751 grades of droughts and floods for each year, including 97 grades from the records of the adjoined counties, in Wuzhou City were created and compiled and assigned grades manually.

\subsection{Reclassifying the Five Grades of Flood and Drought}

At present, the precipitation anomaly percentage method is a very popular and simple approach used to standardize the drought and flood grades in China. This method is often used in meteorology. The anomaly percentage indicates degree to which a value deviates from the long-term average. This value was calculated as follows:

$$
D_{i}=\frac{P_{i}-\bar{P}}{\bar{P}} \times 100 \%
$$

where $D_{i}$ is the precipitation anomaly percentage of $i$-th year; $P_{i}$ is the precipitation of $i$-th year; $\bar{P}$ is the average precipitation over a long period. A higher $D_{i}$ indicates that the precipitation greatly deviates from the average precipitation.

The correlation coefficient $(C C)$ was used in this paper first to measure the relationship between the sequence of flood and drought grades and the measured prescriptions and then to reconstruct the historical precipitation from the sequence of historical flood and drought grades based on the relationship. $C C$ is the linear correlation between two variables and is dimensionless. CC was calculated as follows: 


$$
C C=\frac{\sum_{i=1}^{n}\left(G F L_{i}-\overline{G F L}\right)\left(P_{i}-\bar{P}\right)}{\sqrt{\sum_{i=1}^{n}\left(G F L_{i}-\overline{G F L}\right)^{2} \sum_{i=1}^{n}\left(P_{i}-\bar{P}\right)^{2}}}
$$

where $G F L_{i}$ is the grade of the flood and drought of $i$-th year; $\overline{G F L}$ is the average of these grades.

The root mean square error (RMSE) and relative bias $(R B)$ were used to assess the comparison between the gauged precipitations with the reconstructed precipitations. RMSE and $R B$ were calculated as follows:

$$
\begin{aligned}
& R B=\frac{\sum_{i=1}^{n}\left(P_{r}-P_{g}\right)}{\sum_{i=1}^{n} P_{g}} \times 100 \% \\
& R M S E=\sqrt{\frac{\sum_{i=1}^{n}\left(P_{r}-P_{g}\right)^{2}}{n}}
\end{aligned}
$$

where $n$ is the samples number, $P_{r}$ and $P_{g}$ denote the individually the reconstructed and gauged precipitation, respectively.

A correlation analysis between the sequence of drought and flood grades and the annual precipitation anomaly percentage in Wuzhou City from 1961 to 2000 was conducted; a high correlation was found (CC $=-0.79, n=40)$. We assumed that this relationship is relatively stable and can be extended to the past. This indicates that these variables are strongly correlated and that historical precipitation can be derived from drought and flood records from the same period.

The five grade categories of flood and drought events (Table 1) is too coarse to define an accurate relationship between the grade and annual prescription (a continuous variable). Thus, the five grade categories were decomposed and subdivided to many grades (e.g., 10 or 11,12) based on the inside difference of disaster degree of an original grade corresponding to more precipitation levels [14]. Here, we created many scenarios that defined different relationships of equivalence between the annual precipitation anomaly percentage and the drought and flood grades in Wuzhou City from 1961 to 2000 (Table 2). After many trial-and-error attempts, scenario 3 was selected to reconstruct the annual precipitation due to its low error and high correlation (Table 3), namely, original five grades were subdivided to twelve grades and each new grade has a corresponding anomaly percentage. For example, the annual precipitation anomaly percentage corresponding to the grade 2 flood and drought mostly ranges between $5 \%$ and $25 \%$. In the low-value years, in grade 2 , the historical records mostly described conditions such as "summer June, it rained; or it rained some days". In the high-value years in grade 2, the historical records were mostly written with descriptions such as "soaking and damaging millions of farmlands, seedlings and houses, people and livestock are washed away by the flood". Then, the grade 2 was subdivide to new three grades (high, intermediate and low) and the reconstructed annual precipitation anomaly can be correspondingly assigned to be $21 \%, 14 \%$ and $7 \%$. Among these values, grade 3 (normal) reflects the average annual precipitation and the annual precipitation anomaly percentage was assigned to zero. Through this processing, we built 12 corresponding relationships between flood and drought events and annual precipitation. The average annual precipitation in Wuzhou City is $1489 \mathrm{~mm}$. Thus, the annual precipitation was calculated through the annual precipitation anomaly (Table 3).

Table 2. Three test scenarios with different annual precipitation anomaly percentages.

\begin{tabular}{cccrr}
\hline \multirow{2}{*}{ Scenario } & Annual Precipitation Anomaly & \multirow{2}{*}{ R MSE (mm) } & \multirow{2}{*}{ RB (\%) } \\
\cline { 2 - 5 } & Percentage & & & \\
\hline 1 & $-35 \%,-30 \%,-25 \%,-14 \%,-7 \%, 0,7 \%, 14 \%, 30 \%, 35 \%$ & 164 & $-3.42 \%$ \\
2 & $-35 \%,-30 \%,-25 \%,-14 \%,-7 \%, 0,7 \%, 14 \%, 21 \%, 30 \%, 35 \%$ & 0.82 & 167 & $-3.07 \%$ \\
3 & $-40 \%,-30 \%,-20 \%,-12 \%,-8 \%, 0,7 \%, 14 \%, 21 \%, 25 \%, 30 \%, 40 \%$ & 0.84 & 151 & $-1.95 \%$ \\
\hline
\end{tabular}


Table 3. Precipitation classification standards in Wuzhou City.

\begin{tabular}{|c|c|c|c|c|}
\hline Grade & Allowed for $\mathrm{Mi}$ & Written Example Records & Subdivided Mi & $P(\mathrm{~mm})$ \\
\hline \multirow{3}{*}{1} & \multirow{3}{*}{$\mathrm{Mi}>25 \%$} & $\begin{array}{l}\text { All streets in the city and suburbs of Wuzhou City were flooded. } \\
\text { The entire Wuzhou City was flooded except the two hills and the } \\
\text { four-story buildings. Water depth on the land is approximately } \\
\qquad 3 \mathrm{~m} \text { and many landslides occurred. }\end{array}$ & $40 \%$ & 2085 \\
\hline & & $\begin{array}{c}\text { Floods in Wuzhou and Cangwu were disastrous and heavy. } \\
\text { In a few days, the highest water level in Wuzhou reached } 22.82 \mathrm{~m} \text {. } \\
\text { Half of the houses in Wuzhou were inundated. The farmland was } \\
\text { inundated with more than } 50,000 \text { mu. Thousands of houses were } \\
\text { washed away by the floods. A major flood occurred in Wuzhou, } \\
\text { with a maximum water level of } 24.23 \mathrm{~m} \text {. }\end{array}$ & $30 \%$ & 1936 \\
\hline & & $\begin{array}{l}\text { Heavy rains in July, houses were washed away and the fields near } \\
\text { the river were all flooded; in September, the river destroyed } \\
\text { farmlands. The flood flooded the walls. }\end{array}$ & $25 \%$ & 1861 \\
\hline \multirow[t]{2}{*}{2} & \multirow[t]{2}{*}{$5 \%<\mathrm{Mi}<25 \%$} & $\begin{array}{l}\text { Floods occurred in the summer and houses in the southeast of the } \\
\text { city were flooded. A flood occurred in July and the water level in } \\
\text { Wuzhou was } 21.50 \mathrm{~m} \text {. In May, floods damaged crops and people } \\
\text { were hungry. Summer and autumn floods occurred. }\end{array}$ & $14 \%$ & 1698 \\
\hline & & Summer, June, it rained; it rained some days. & $7 \%$ & 1594 \\
\hline 3 & $-5 \%<\mathrm{Mi}<5 \%$ & The climate is normal and no flood and drought occurred. & $0 \%$ & 1489 \\
\hline \multirow[b]{2}{*}{4} & \multirow[b]{2}{*}{$\begin{array}{c}-15 \%<\mathrm{Mi} \\
<-5 \%\end{array}$} & Drought. & $-8 \%$ & 1370 \\
\hline & & $\begin{array}{l}\text { May to autumn drought, people are hungry. There is a famine. } \\
\text { The area affected by drought was approximately } 100,000 \mathrm{mu} \text {. } \\
\text { The rent of drought farmland was exempted. }\end{array}$ & $-12 \%$ & 1310 \\
\hline 5 & $\mathrm{Mi}<-15$ & $\begin{array}{l}\text { Severe drought, no harvest. The food is very expensive. Refugees } \\
\text { were everywhere and many people died and were sold due to the } \\
\text { drought. The drought-affected area was approximately } \\
300,000 \mathrm{mu} \text {. }\end{array}$ & $-40 \%$ & 894 \\
\hline
\end{tabular}

Note: Mi is annual precipitation anomaly percentage.

\section{Results}

\subsection{Droughts and Floods in the History of Wuzhou}

The magnitude of the geographical variables for different periods is affected by both dominant and accidental factors. To clearly express the trend over a long period, the sequence of floods and droughts over 800 years was subjected to a 25-year moving average (Figure 2). Figure 2 clearly shows that flood and drought grades significantly declined at the 0.01 significance level $\left(C C^{2}=0.30\right)$. This indicates that Wuzhou City tends to be wet. Furthermore, large flood events in Wuzhou City were more frequent after the 1630s, as indicated by the large fluctuations in the trend line and the observation that most of the trend line occurs under grade 3 (Figure 2). 


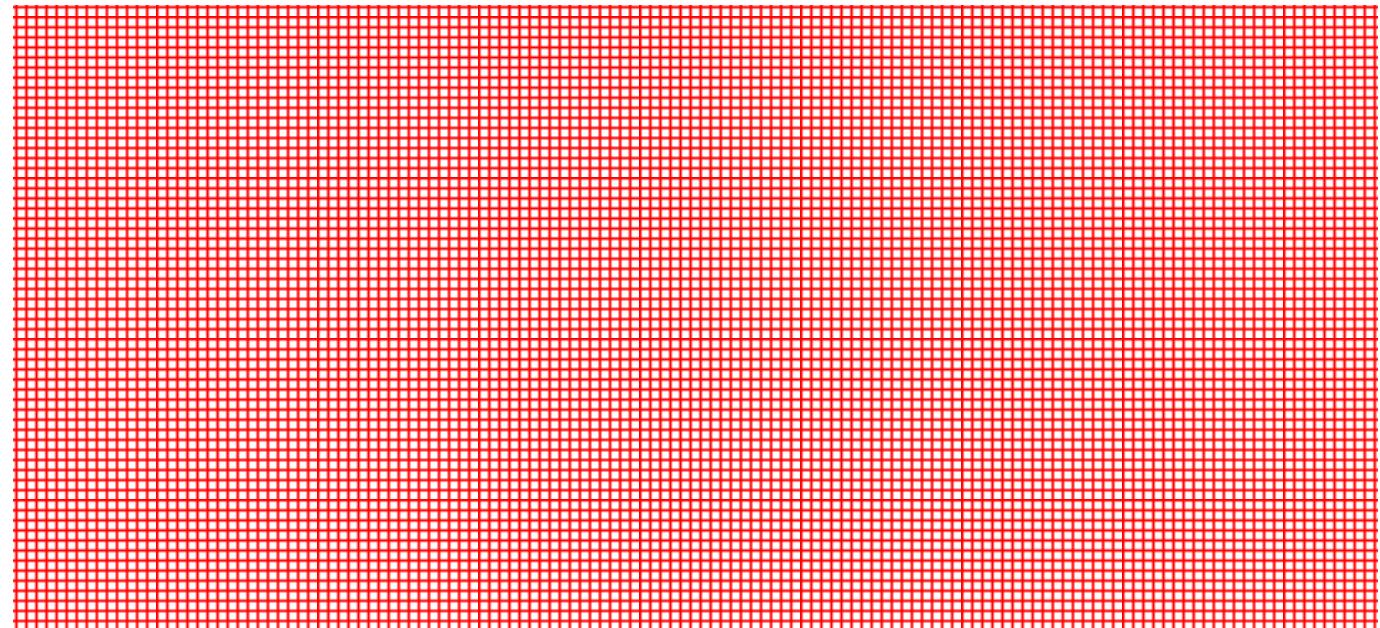

Figure 2. A 25-year moving average of drought and flood grades in Wuzhou City.

Figure 3 shows that there were 16 events of grade 1 (very wet) and 186 events of grade 2 (wet) which accounts for $26.90 \%$ of the total events in the past 800 years. Compared to flood events, drought events are smaller and only account for $14.11 \%$ of the total events, as indicated by the small number of grade 4 events (dry). Waterlogging was the main disaster in Wuzhou City and often occurred in the summer according to historical documents.

Figure 4 shows the difference between two periods (1250-1360s and 1360s-2000). We find that large flood and drought events (of grade 1 and grade 5) increased, while general floods (grade 2) exhibited triple-digit growth after the 1360s. This is consistent with the results shown in Figure 3.

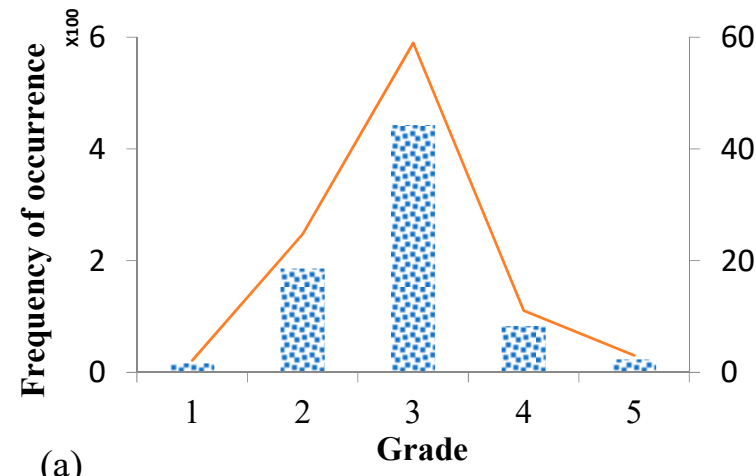

Frequency of occurrence - Proportion

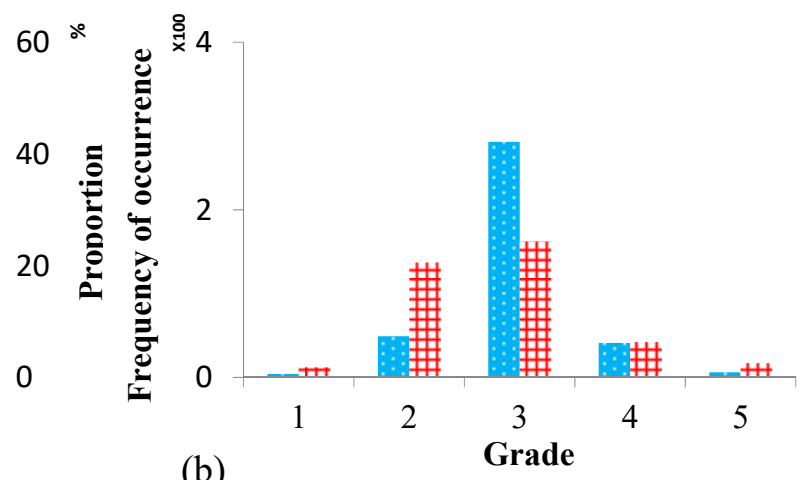

a $1250 \sim 1360 \quad \pm 1360 \sim 2000$

Figure 3. Statistics on the frequency of droughts and floods over past 800 years (a) and in two periods, from 1250-1360 and 1360-2000 (b) in Wuzhou City.

\subsection{Reconstruction of Precipitation in Wuzhou City}

According to the aforementioned approach, the 800-year sequence of drought and flood grades was converted into a precipitation sequence (Table S1). Figure 4 shows the 25 -year moving average of the reconstructed precipitation sequence and linear polynomial fitting was also conducted in Figure 4 to express the change trends. In general, the annual precipitation in Wuzhou City has experienced linear growth above the 0.01 significance level $\left(C C^{2}=0.24\right)$. At a small scale, we found fluctuation in the precipitation change. Based on the polynomial curve $\left(C C^{2}=0.45\right)$, the entire precipitation period could be roughly divided into four stages (an increasing stage of the 14-15th century, a decreasing stage of the 16-17th century, an increasing stage of the 18-19th century and a decreasing stage of the 20th century). 


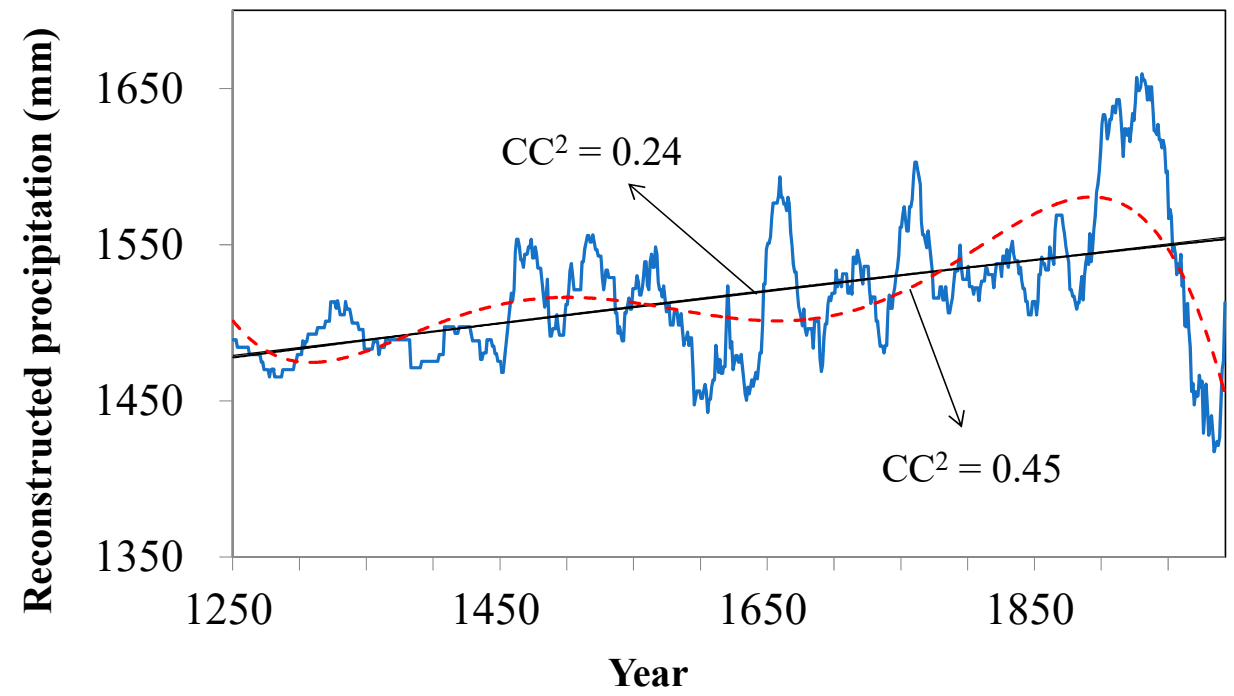

Figure 4. Precipitation 25-year moving average (blue curve), linear fit (black line) and polynomial fitting (red curve), nearly eight hundred years in Wuzhou City.

\section{Discussion}

In China, well-dated documentary records illustrate a precise sequence of flood and drought events over the last few thousand years due to the long history of civilization [20], which is advantageous for reconstructing precipitation. Compared to other proxy data, such as tree rings, lake sediments, ice cores and sporopollen, historical documents are advantageous because Guangxi is located in an area of tropical monsoon climate and subtropical monsoon climate, with rain and heat occurring during the same period and no large lake present (the water surface equals $1 \mathrm{~km}^{2}$ ). Thus, Wuzhou City, Guangxi, southwest China, a city with a long historical records, was selected to reconstruct the precipitation of the past 800 years to fill gaps in southwest China. By using historical records of flood and drought events, a sequence of flood and drought grades was reconstructed and then the annual precipitation sequence was reconstructed according to the correlation between the flood and drought grades and the precipitation anomaly percentages.

According to our reconstructed flood and drought sequence (Figure 2), flood and drought events were more severe after the 1630s. This is likely due to global warming increasing the flood and high-temperature events. The warming trend in the past 500 years in the Northern Hemisphere is significant based on many reconstruction studies [21,22] and is consistent with the estimated ground surface temperature trends from temperature measurements in nearly 700 boreholes [23]. In addition, Figure 2 also implies that more floods will probably occur in the future. The government should raise the flood control standards of Wuzhou City. According to the latest Flood Control Planning of Wuzhou City (2013-2030) in 2017, the control standards will be generally improved. As for urban areas of Wuzhou City, the standards will up to once in a hundred years.

The annual precipitation sequence reconstructed from 1961 to 2000 in Wuzhou City was compared with the measured precipitations from Wuzhou meteorological station, as shown in Figure 5. It can be seen in the figure that the reconstructed precipitation and the measured precipitation curve are highly convergent and the trend and the important inflection points are relatively consistent. Moreover, the correlation coefficient is 0.83 , the relative error is $-0.21 \%$ and the absolute error is $-104 \mathrm{~mm}$. Therefore, the reconstructed annual precipitation sequence is accurate and credible. 
(a)

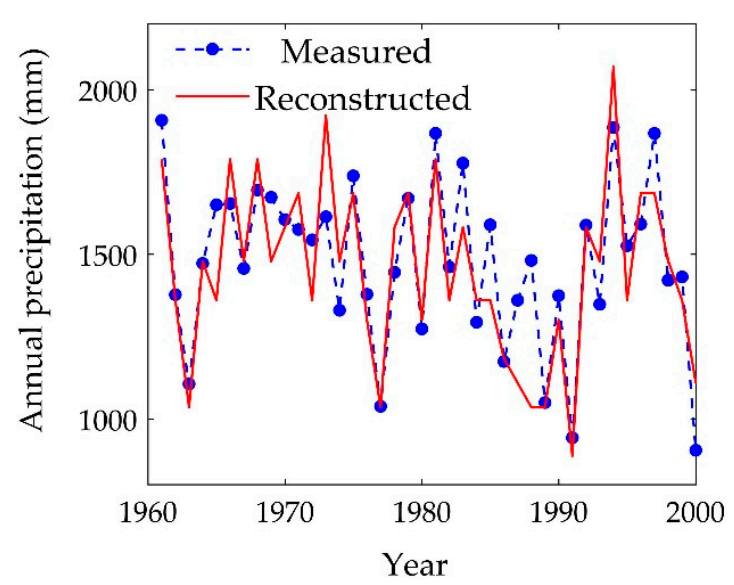

(b)

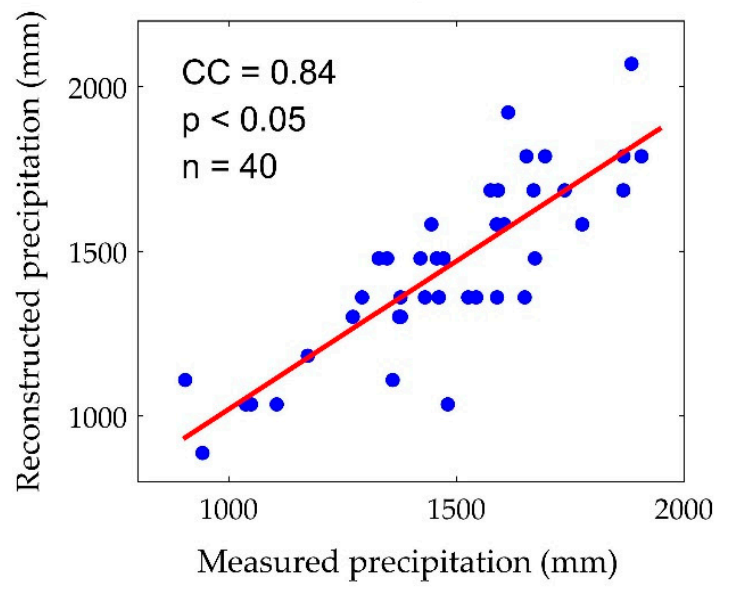

Figure 5. Comparison of reconstructed precipitation and measured precipitation through (a) line chart and (b) scatter plot in Wuzhou City from 1961 to 2000.

Figure 6 shows that the change trend of natural annual runoffs is basically consistent with the reconstructed precipitations $\left(C C^{2}=0.52\right)$, which implies that the change of annual runoff is controlled by climate change. This was found to coincide with Zhu's results [24]. Furthermore, natural annual runoff drastically fluctuated in the range from 308 to 107 billion $\mathrm{m}^{3}$ over the past 55 years. To respond to climate change, adaptive water management may be a suitable tool to be applied in water management planning in Wuzhou City.

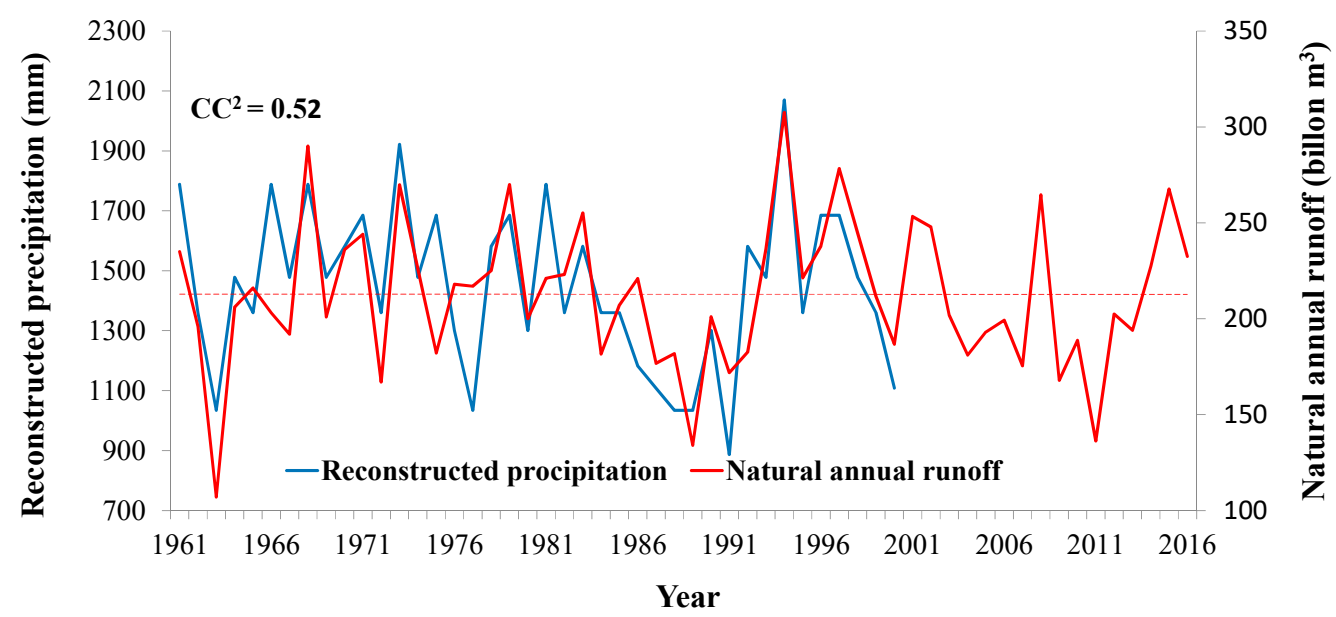

Figure 6. Changes of the reconstructed precipitations (1961-2000) and natural annual runoffs (1961-2016) at Wuzhou station from 1961 to 2000. Red broken line is the linear fit of natural annual runoffs.

Three limitations of this study should be noted. First, the compilation of historical records may be somewhat subjective because of the process of converting verbal descriptions to grade values. Second, we can only validate the reconstructed precipitation from 1961-2000 due to a lack of historical measurements. Third, the reconstructed precipitation may have uncertainty. The stable relationship between drought and flood grades and the annual precipitation anomaly percentage we assumed and extended to the past may be unstable due to climate change. The eastern monsoon region of China has sufficient water and heat and there are many rivers in this region; therefore, precipitation is not the only factor to affect waterlogging conditions, as these conditions are also affected by upstream water volume. For example, a waterlogging event occurred only once in ten years in July 1962 but the local measured rainfall was lower than the multiyear average. This situation leads to a lower correlation 
between the measured precipitation and the predicted precipitation in the monsoon region than is found for arid and semiarid regions. In addition, there are still missing data in the sequence of flood and drought records.

\section{Conclusions}

We need to know the past to predict the future. Reconstructions of floods, droughts and annual precipitation in Wuzhou City over the past 800 years provide essential information about climate change and water resources in southwest China. The main conclusions of this paper can be summarized as follows:

(1) Over the past 800 years, flood and drought events in Wuzhou City were frequent and more floods occurred over the long term.

(2) There is a break in the flood and drought sequence in the 1630s. The flood and drought events were more severe after the 1630s.

(3) The reconstructed precipitation is credible because it is highly correlated (correlation coefficient 0.84 with the measured precipitation from the last 40 years) and has a low relative error $(-1.95 \%)$ and absolute error $(-104 \mathrm{~mm})$.

(4) The annual precipitation in Wuzhou City significantly increased over the past 800 years. At the small scale, there are four periods of annual precipitation change (the increasing stage of the 14-15th century and the 18-19th century and the decreasing stage of the 16-17th and the 20th century).

Supplementary Materials: The following are available online at http:/ /www.mdpi.com/2073-4441/11/2/219/s1, Table S1: The reconstructed precipitations at Wuzhou City.

Author Contributions: Y.Z. designed the experiment and wrote the paper, N.Y., B.H., Q.C., K.T. and Y.L. collected data, N.Y. completed the experiment, Y.W. revised and commented the paper. All authors have read and approved the final manuscript.

Funding: This study was financially supported by the project "Specially Employed Expert" of Guangxi Zhuang Autonomous Region (2017B17) and the National Natural Science Foundation of China (41661085, 41807012 and 11664004).

Acknowledgments: The authors would like to thank anonymous referees and the editor for their very helpful comments on an earlier draft of this paper.

Conflicts of Interest: The authors declare no conflict of interest.

\section{References}

1. Liu, P.X. Advances in Dendrohydrology around the World. J. Glaciol. Geocryol. 2004, 6, 720-728. (In Chinese)

2. Lu, Z.; Wei, Y.; Feng, Q.; Xie, J.; Xiao, H.; Cheng, G. Co-evolutionary dynamics of the human-environment system in the Heihe River basin in the past 2000 years. Sci. Total Environ. 2018, 635, 412-422. [CrossRef]

3. Lu, Z.; Wei, Y.; Xiao, H.; Zou, S.; Xie, J.; Ren, J.; Western, A. Evolution of the human water relationships in Heihe River basin in the past 2000 years. Hydrol. Earth Syst. Sci. 2015, 12, 1059-1091. [CrossRef]

4. Woodhouse, C.A.; Overpeck, J.T. 2000 Years of Drought Variability in the Central United States. Bull. Am. Meteorol. Soc. 1998, 79, 2693-2714. [CrossRef]

5. Zhu, K.Z. Preliminary Study on Climate Change in China in the Past 5000 Years. Sci. China 1972, 1, 15-38. (In Chinese)

6. Zheng, J.Y.; Hao, Z.X.; Ge, Q.S. Variation of precipitation for the last 300 years over the middle and lower reaches of the Yellow River. Sci. China Ser. D Earth Sci. 2005, 48, 2182-2193. [CrossRef]

7. Gou, X.H.; Deng, Y.; Gao, L.L.; Chen, F.H.; Cook, E.; Yang, M.X.; Zhang, F.Z. Millennium tree-ring reconstruction of drought variability in the eastern Qilian Mountains, Northwest China. Clim. Dyn. 2015, 45, 1761-1770. [CrossRef]

8. Bird, B.W.; Polisar, P.J.; Lei, Y.B.; Thompson, L.G.; Yao, T.D.; Finney, B.P.; Bain, D.J.; Pompeani, D.P.; Steinman, B.A. A Tibetan lake sediment record of Holocene Indian summer monsoon variability. Earth Planet. Sci. Lett. 2014, 399, 92-102. [CrossRef] 
9. Mock, C.J. Historical evidence of a cold, dry summer during 1849 in the northeastern Great Basin and adjacent Rocky Mountains. Clim. Chang. 1991, 18, 37-66. [CrossRef]

10. Rodrigo, F.S.; Esteban-Parra, M.J.; Castro-Diez, Y. An attempt to reconstruct the rainfall regime of andalusia (southern Spain) from 1601 A.D. to 1650 A.D. using historical documents. Clim. Chang. 1994, 27, 397-418. [CrossRef]

11. Zhang, P.; Ge, Q.; Zhang, S.; Liu, X. The Modes and Abrupt Changes of Climate in China During Decent 2000 Years. Quat. Sci. 1997, 17, 12-20.

12. Zhang, D.; Liu, C.; Jianmin, J. Reconstruction of six regional dry/wet series and their abrupt changes during the last 1000 years in east China. Quat. Sci. 1997, 17, 1-11.

13. Rong, Y.S.; Tu, Q.P. Reconstruction of 500-Year Moving-Average Precipitation Field Series in North China. Meteorol. Sci. Technol. 2004, 32, 163-167. (In Chinese)

14. Ren, Z.X.; Lu, Y.Q.; Yang, D.Y. Drought and flood disasters and rebuilding of precipitation sequence in Heihe River basin in the past 2000 years. J. Arid Land Resour. Environ. 2010, 24, 91-95. (In Chinese)

15. Zhang, Q.; Gu, X.; Singh, V.P.; Shi, P.; Sun, P. More frequent flooding? Changes in flood frequency in the Pearl River basin, China, since 1951 and over the past 1000 years. Hydrol. Earth Syst. Sci. 2018, 22, 2637-2653. [CrossRef]

16. Song, J. Reconstruction of the southern oscillation from dryness/wetness in China for the last 500 years. Int. J. Climatol. J. R. Meteorol. Soc. 1998, 18, 1345-1355. [CrossRef]

17. He, Z.; He, Y.; Wang, S.; Pang, J.; Xin, H.; Liu, J. Reconstruction and comparative analysis of dry/wet series since 1470-2008 ad in northwest China. J. Desert Res. 2016, 36, 1278-1285.

18. Ge, Q.S.; Zheng, J.Y.; Hao, Z.X.; Liu, Y.; Li, M.Q. Recent advances on reconstruction of climate and extreme events in China for the past 2000 years. J. Geogr. Sci. 2016, 26, 827-854. [CrossRef]

19. Chinese Academy of Meteorological Sciences, China Meteorological Administration. Yearly Charts of Dryness/Wetness in China for the Last 500-Year Period; SinoMaps Press: Beijing, China, 1981. (In Chinese)

20. Bradley, R.S.; Sheu, D.; Wang, W.C. High-resolution paleoclimate records from monsoon Asia. Eos Trans.-Am. Geophys. Union 1993, 74, 601-604. [CrossRef]

21. Jones, P.D.; Moberg, A. Hemispheric and large-scale surface air temperature variations: An extensive revision and an update to 2001. J. Clim. 2003, 16, 206-223. [CrossRef]

22. Mann, M.E.; Jones, P.D. Global surface temperatures over the past two millennia. Geophys. Res. Lett. 2003, 30, 1820. [CrossRef]

23. Pollack, H.N.; Smerdon, J.E. Borehole climate reconstructions: Spatial structure and hemispheric averages. J. Geophys. Res. 2004, 109. [CrossRef]

24. Zhu, Y.J.; Guo, C.Q.; Huang, X.K. Change of precipitation and runoff at Wuzhou station on Xijiang River under influence of climate changes and human activities. J. China Hydrol. 2010, 30, 50-55. (In Chinese) 